\title{
Abordagem das bactérias extremófilas em livros didáticos de biologia do ensino médio
}

Approach of extremophil bacteria in educational books of medium education biology

\author{
C. R. S. Santos; H. F. Braga* \\ Instituto Federal de Educação, Ciência e Tecnologia do Triângulo Mineiro Campus Uberlândia Centro, 38411-104, \\ Uberlândia-MG, Brasil \\ *heberly@iftm.edu.br
}

(Recebido em 24 de abril de 2019; aceito em 13 de setembro de 2019)

Os livros didáticos são os instrumentos de ensino mais acessíveis aos professores nas escolas, sendo primordial que os conteúdos possam ser contemplados da forma mais ampla possível. O tema arqueas, merece ser pontuado nesses materiais, especialmente pelos recentes avanços tecnológicos que possibilitam o emprego de tais micro-organismos em diversas áreas. Neste sentido, foram analisadas oito obras didáticas de Biologia do Ensino Médio segundo os aspectos gerais de Coerência e Conceitos, Quantificação e Interdisciplinaridade e Contextualização das bactérias extremófilas, tendo por base o guia do Programa Nacional do Livro Didático do Ministério da Educação. Os critérios "aplicações biotecnológicas e adaptações bioquímicas" foram os que apresentam as maiores defasagens em relação à abordagem do assunto, na maioria das obras didáticas. No geral, somente uma obra teve boa avaliação em todos os aspectos analisados. Quanto ao critério "coerência entre fundamentação teórica e, imagens, textos e exercícios propostos", todas as obras apresentaram-se satisfatórias. Portanto, apesar de as discussões sobre esse tema serem de suma importância ao contexto atual, as obras apresentam deficiências técnicas, em especial no que tange às aplicações biotecnológicas.

Palavras-chave: Archaea, ensino de microbiologia, procariontes extremófilos.

Textbooks are the most accessible teaching tools for teachers in schools, and it is essential that the contents can be contemplated in the widest possible way. The subject archaea deserves to be punctuated in these materials, especially by the recent technological advances that allow the use of such microorganisms in several areas. In this sense, eight didactic works of Teaching Biology were analyzed according to the general aspects of Coherence and Concepts, Quantification and Interdisciplinarity and Contextualization of the extremophilic bacteria, based on the guide of the National Program of Didactic Book of the Ministry of Education. The criteria "biotechnological applications and biochemical adaptations" were the ones with the greatest lags in relation to the subject approach in most didactic works. In general, only one work had good evaluation in all aspects analyzed. As to the criterion "coherence between theoretical foundation and images, texts and proposed exercises", all works were satisfactory. Therefore, although the discussions on this subject are of the utmost importance to the current context, the works present technical deficiencies, especially in what concerns the biotechnological applications.

Keywords: Archaea, teaching of microbiology, extremophile prokaryotes.

\section{INTRODUÇÃO}

Segundo o educador brasileiro Paulo Freire (2017) [1], um dos estudiosos da pedagogia crítica, o ato de "ler criticamente o mundo" é superior e precedente "à leitura da palavra", isto porque, antes da mera decodificação dos códigos, os aprendizes analisam e comparam aquilo que é simbolizado com o contexto anterior por eles vivenciado [1]. Tal experiência pode também ser refletida na relação estudante-livro didático.

O Livro Didático (LD) é um material escolar muito importante e o mais acessível aos professores e discentes das instituições de ensino públicas e privadas de educação básica. Funciona como um dos apoios direcionadores das aulas, permitindo uma apresentação lógica e coerente dos conteúdos a serem apreendidos, sendo inclusive usado pelos docentes, ao longo da preparação das aulas, como instrumento de revisão e atualização de conhecimentos e conteúdos pertinentes à determinada área. Daí a importância da relação que o livro didático deve ter com os avanços técnicos e de conhecimento do mundo.

A dinamicidade e pluralidade do mundo pós-moderno [2], tem exigido dos educadores uma maior criticidade na análise e adoção de instrumentos de ensino-aprendizagem que possam fidelizar 
os avanços pelos quais o conhecimento tem passado, e ao mesmo tempo permitir uma maior explanação e detalhamento do conteúdo a ser ensinado [3]. Nesse sentido, a seleção dos LDs a serem empregados como materiais de suporte ao ensino, faz-se necessária.

Para que os professores selecionem da melhor forma os livros que serão utilizados pelos estudantes durante as aulas, o Programa Nacional do Livro Didático - PNLD [4], possui parâmetros de avaliação que compreendem alguns aspectos didáticos gerais utilizados também como parâmetros pelo presente estudo: Coerência e Conceitos; Quantificação; Interdisciplinaridade e Intertextualidade.

O parâmetro Coerência e Conceitos refere-se à ligação entre textos, imagens e exercícios propostos e à utilização de conceitos adequados e corretos. No que diz respeito ao aspecto de Quantificação, são analisados a quantidade de iconográficos, páginas e capítulos relacionados ao tema. Interdisciplinaridade e Intertextualidade estendem-se às contextualizações com outras áreas do conhecimento bem como às adaptações bioquímicas, aplicações biotecnológicas e a abordagem de diferentes tipos de Archaea.

Referir-se às arqueas enquanto "bactérias" é um termo errôneo, visto que tal denominação remete a micro-organismos de outro domínio taxonômico de seres vivos. Deste modo, alguns autores optam pelo termo "bactéria extremófila", outros por "arquea", no entanto o modo de se referir a estes micro-organismos é somente um detalhe ao observarmos tamanha a capacidade de se desenvolverem otimamente em ambientes considerados inóspitos para grande parte dos seres vivos. Na indústria, seja ela alimentícia, de limpeza, têxtil, de mineração, na área da genética ou mesmo em outros setores, o emprego das arqueas e/ou seus metabólitos podem atuar de forma específica e fundamental, otimizando os processos e reduzindo o custo e tempo demandado para produção [5].

Nesse sentido, objetivou-se analisar como o tema Archaea é desenvolvido em alguns LDs de Biologia elencados pelo PNLD 2018-2020 do Ministério da Educação, segundo parâmetros didáticos de avaliação indicados pelo mesmo órgão.

\section{MATERIAL E MÉTODOS}

Obras didáticas (Tabela 1) destinadas às três etapas do ensino médio $\left(1^{\circ}, 2^{\circ}\right.$ e $3^{\circ}$ anos), foram doadas como cortesia pelas editoras, sendo oito delas selecionadas aleatoriamente para serem avaliadas entre um total de 12 indicadas no PNLD 2018. Dentre as obras selecionadas, encontramse livros de autores consagrados e recorrentemente adotados pelas escolas como instrumento didático apoiador do ensino de Biologia e autores recentes que empregam abordagens didáticas diferenciadas.

Quadro 1: Obras didáticas selecionadas do Guia do LD de ensino médio - Biologia.

\begin{tabular}{|l|l|c|c|c|}
\hline \multicolumn{1}{|c|}{ Título do Livro } & \multicolumn{1}{|c|}{ Autor(es) } & Editora & Ano & Designação \\
\hline Biologia & Vivian L. Mendonça & AJS & 2016 & LD1 \\
\hline Biologia & Sônia Lopes / Sergio Rosso & Saraiva & 2016 & LD2 \\
\hline Biologia & $\begin{array}{l}\text { César da S. Júnior / Sezar Sasson / Nelson } \\
\text { Caldini Júnior }\end{array}$ & Saraiva & 2016 & LD3 \\
\hline Biologia Hoje & $\begin{array}{l}\text { Sérgio Linhares / Fernando } \\
\text { Gewandsznajder / Helena Pacca }\end{array}$ & Ática & 2016 & LD4 \\
\hline $\begin{array}{l}\text { Biologia Moderna: Amabis } \\
\text { \& Martho }\end{array}$ & $\begin{array}{l}\text { José Mariano Amabis / Gilberto } \\
\text { Rodrigues Martho }\end{array}$ & Moderna & 2016 & LD5 \\
\hline Conexões com a Biologia & Miguel Thompson / Eloci Peres Rios & Moderna & 2016 & LD6 \\
\hline
\end{tabular}




\begin{tabular}{|l|l|c|c|c|}
\hline Biologia: Novas Bases & Nélio Bizzo & IBEP & 2016 & LD7 \\
\hline $\begin{array}{l}\text { Biologia Unidade e } \\
\text { Diversidade }\end{array}$ & José Arnaldo Favaretto & FTD & 2016 & LD8 \\
\hline
\end{tabular}

Fonte: Brasil (2017) [4].

A avaliação das obras didáticas foi feita qualitativamente por meio da leitura sistematizada dos capítulos de todos os volumes, tendo como parâmetro analítico balizador os três aspectos baseados no PNLD 2018 [4] (Quadro 2).

Quadro 2: Aspectos e critérios para análise do tema bactérias extremófilas em livros didáticos de biologia do PNLD 2018.

\begin{tabular}{|c|c|}
\hline $\begin{array}{l}\text { Aspectos analisados nos livros didáticos de } \\
\text { Biologia PNLD } 2018\end{array}$ & Critérios em análise \\
\hline \multirow{3}{*}{ I Coerência e Conceitos } & $\begin{array}{l}\text { - Coerência entre fundamentação teórica e: imagens, } \\
\text { textos e exercícios propostos }\end{array}$ \\
\hline & - Emprego de conceitos corretos ou fragmentados \\
\hline & - Uso de vocabulário adequado e atualizado \\
\hline \multirow{3}{*}{$\begin{array}{c}\text { II } \\
\text { Quantificação }\end{array}$} & - Iconográficos apresentados \\
\hline & - Número de páginas dedicadas ao assunto \\
\hline & - Capítulos que abordam o tema \\
\hline \multirow{4}{*}{$\begin{array}{c}\text { III } \\
\text { Interdisciplinaridade e Contextualização }\end{array}$} & - Contextualização e integração com outros temas \\
\hline & - Aplicações biotecnológicas \\
\hline & - Adaptações bioquímicas \\
\hline & $\begin{array}{l}\text { - Abordagem dos diferentes grupos de procariontes } \\
\text { extremófilos }\end{array}$ \\
\hline
\end{tabular}

Fonte: Adaptado de Brasil (2017) [4].

Visando-se quantificar o atendimento ou não em relação aos parâmetros recomendados pelo PNLD 2018, foram atribuídas notas (Quadro 3) às obras didáticas, de 1 (um) a 5 (cinco), conforme determinado critério analisado (Quadro 4), tendo por base escala desenvolvida por Peixe et al. (2017) [6]. Histogramas de frequência foram empregados como estratégia para comparar graficamente as notas atribuídas as obras didáticas avaliadas, segundo os aspectos e critérios parametrizados pelo PNLD.

Quadro 3: Valores numéricos atribuídos à avaliação obras didáticas.

\begin{tabular}{|c|c|}
\hline \multicolumn{2}{|c|}{ Notas de Avaliação } \\
\hline Notas & Classificação \\
\hline 1 & A obra não atende ao requisito. \\
\hline 2 & A obra atende de modo insuficiente ao requisito. \\
\hline
\end{tabular}




\begin{tabular}{|c|l|}
\hline 3 & A obra atende parcialmente ao requisito. \\
\hline 4 & A obra atende satisfatoriamente ao requisito. \\
\hline 5 & A obra atende plenamente ao requisito. \\
\hline
\end{tabular}

Fonte: Peixe et al. (2017) [6].

Quadro 4: Critérios adotados para a parametrização das notas de avaliação das obras didáticas.

\begin{tabular}{|c|c|c|c|c|}
\hline \multicolumn{5}{|c|}{ Coerência e Conceitos } \\
\hline \multirow[t]{2}{*}{ Notas } & \multicolumn{4}{|c|}{ Critérios de nota } \\
\hline & $\mathbf{A}$ & $\mathbf{B}$ & & $\mathbf{C}$ \\
\hline 1 & 4 ou + incoerências & $\begin{array}{l}4 \mathrm{ou}+\text { conceitos } \\
\text { incorretos }\end{array}$ & \multicolumn{2}{|c|}{$\begin{array}{c}4 \mathrm{ou}+\text { usos inadequados e } \\
\text { desatualizados }\end{array}$} \\
\hline 2 & 3 incoerências & 3 conceitos incorretos & \multicolumn{2}{|c|}{3 usos inadequados e desatualizados } \\
\hline 3 & 2 incoerências & 2 conceitos incorretos & \multicolumn{2}{|c|}{2 usos inadequados e desatualizados } \\
\hline 4 & 1 incoerência & 1 conceito incorreto & \multicolumn{2}{|c|}{1 uso inadequado e desatualizado } \\
\hline 5 & $\begin{array}{l}\text { Nenhuma } \\
\text { incoerência }\end{array}$ & $\begin{array}{l}\text { Nenhum conceito } \\
\text { incorreto }\end{array}$ & \multicolumn{2}{|c|}{$\begin{array}{c}\text { Nenhum uso inadequado e } \\
\text { desatualizado }\end{array}$} \\
\hline \multicolumn{5}{|c|}{ Quantificação } \\
\hline Notas & \multicolumn{4}{|c|}{ Critérios de nota } \\
\hline & $\mathbf{D}$ & $\mathbf{E}$ & & $\mathbf{F}$ \\
\hline 1 & $\begin{array}{l}\text { Nenhum } \\
\text { iconográfico }\end{array}$ & Nenhuma página & \multicolumn{2}{|c|}{ Nenhum capítulo } \\
\hline 2 & 1 iconográfico & 1 página & \multicolumn{2}{|c|}{1 capítulo } \\
\hline 3 & 2 iconográficos & 2 páginas & \multicolumn{2}{|c|}{2 capítulos } \\
\hline 4 & 3 iconográficos & 3 páginas & \multicolumn{2}{|c|}{3 capítulos } \\
\hline 5 & $\begin{array}{c}4 \text { ou }+ \\
\text { iconográficos }\end{array}$ & 4 ou + páginas & \multicolumn{2}{|c|}{4 ou + capítulos } \\
\hline \multicolumn{5}{|c|}{ Interdisciplinaridade e Contextualização } \\
\hline Notas & \multicolumn{4}{|c|}{ Critérios de nota } \\
\hline & $\mathbf{G}$ & $\mathbf{H}$ & $\mathbf{I}$ & $\mathbf{J}$ \\
\hline 1 & Nenhum tema & Nenhuma aplicação & $\begin{array}{l}\text { Nenhum } \\
\text { exemplo }\end{array}$ & $\begin{array}{l}\text { Nenhum micro- } \\
\text { organismo }\end{array}$ \\
\hline 2 & 1 tema & 1 aplicação & 1 exemplo & 1 micro-organismo \\
\hline 3 & 2 temas & 2 aplicações & 2 exemplos & 2 micro-organismos \\
\hline
\end{tabular}




\begin{tabular}{|c|c|c|c|c|}
\hline 4 & 3 temas & 3 aplicações & 3 exemplos & 3 micro-organismos \\
\hline 5 & 4 ou + temas & 4 ou + aplicações & $\begin{array}{c}4 \text { ou }+ \\
\text { exemplos }\end{array}$ & $\begin{array}{c}4 \text { ou }+ \text { micro- } \\
\text { organismos }\end{array}$ \\
\hline
\end{tabular}

Fonte: Adaptado de Peixe et al. (2017) [6]. A = Coerência entre fundamentação teórica e imagens, textos e exercícios propostos. $\mathrm{B}=$ Emprego de conceitos corretos ou fragmentados. $\mathrm{C}=$ Uso de vocabulário adequado e atualizado. $\mathrm{D}=$ Iconográficos apresentados. $\mathrm{E}=$ Número de páginas dedicadas ao assunto. $\mathrm{F}=$ Capítulos que abordam o tema. $\mathrm{G}=$ Contextualização e integração com outros temas. $\mathrm{H}=$ Aplicações biotecnológicas. $\mathrm{I}$ = Adaptações bioquímicas. $\mathrm{J}=$ Abordagem dos diferentes grupos de procariontes extremófilos.

\section{RESULTADOS}

\subsection{Coerência e Conceitos}

O aspecto geral "Coerência e Conceitos" é cumprido de forma plena em todas as obras analisadas, com exceção da LD5 (Figura 1) que não atendeu satisfatoriamente o critério "emprego de conceitos corretos ou fragmentados".

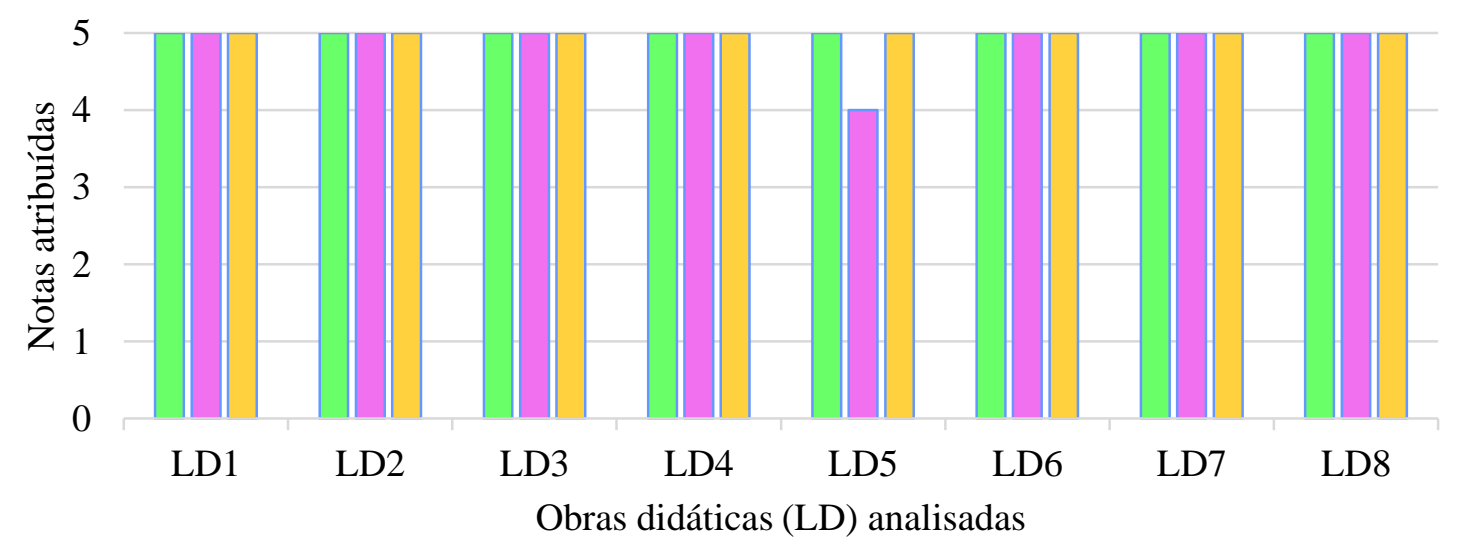

$\square$ Coerência entre fundamentação teórica e imagens, textos e exercícios propostos

$\square$ Emprego de conceitos corretos ou fragmentados

$\square$ Uso de vocabulário adequado e atualizado

Figura 1: Notas atribuídas às obras didáticas, por escala numérica adaptada de Peixe et al. (2017) [6], ao aspecto Coerência e Conceitos, segundo os diferentes critérios avaliados e parametrizados pelo PNLD 2018.

\subsection{Quantificação}

Das obras analisadas, $25 \%$ receberam nota 2 , por apresentarem apenas um iconográfico relacionado às arqueas; outras $25 \%$ receberam nota 3 , por apresentar dois iconográficos; $12,5 \%$ das obras didáticas receberam nota 4 , pois apresentaram três iconográficos e 37,5\% cumpriram plenamente o requisito, apresentando 4 ou mais iconográficos.

Em relação ao "número de páginas dedicadas ao assunto", $25 \%$ das obras cumpriram o critério de forma satisfatória, ao passo que somente a LD8 obteve nota 3 (cumpre parcialmente). As demais obras didáticas cumprem o requisito de forma plena.

Os conteúdos Archaea, Biotecnologia, Domínios Biológicos, Origem da Vida e Quimiossíntese foram analisados e quantificados quanto à abordagem da temática "bactérias extremófilas / arqueas", e foi percebido que somente os livros das obras LD3, LD5 e LD6 explanaram a temática em todos os conteúdos (Figura 2). 


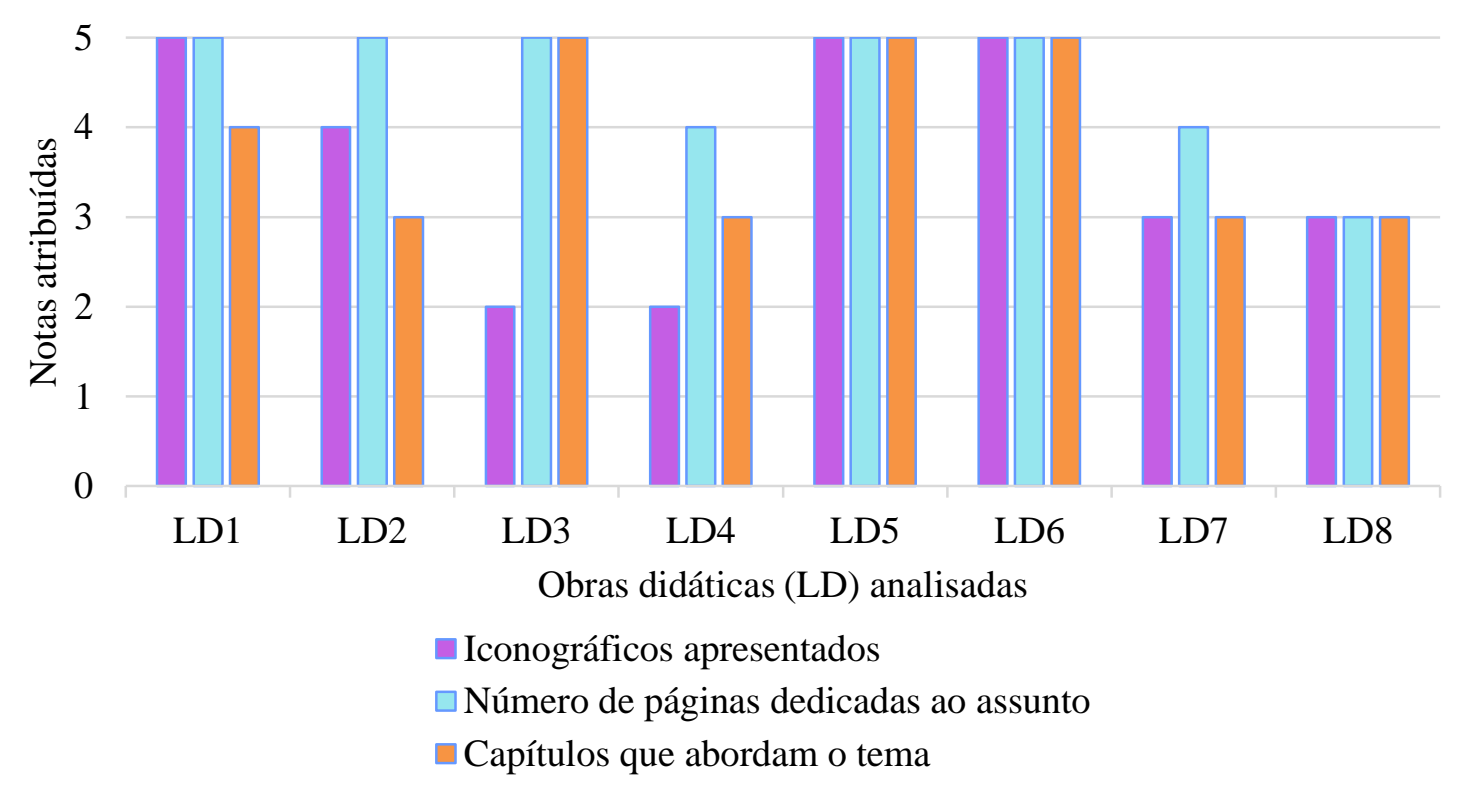

Figura 2: Notas atribuídas às obras didáticas, por escala numérica adaptada de Peixe et al. (2017) [6], ao aspecto Quantificação, segundo os diferentes critérios avaliados e parametrizados pelo PNLD 2018.

\subsection{Interdisciplinaridade e Contextualização}

No que tange à "intertextualidade e integração", as obras LD2, LD3, LD4 e LD6 fazem referências às arqueas no conteúdo de "Biotecnologia", enquanto que no conteúdo "Domínios Biológicos" a temática é apresentada em todas as obras analisadas; e em "Origem da Vida" e "Quimiossíntese", o assunto aparece somente em LD3, LD5 e LD6 e LD1, LD2, LD3, LD5, LD6, respectivamente.

Dentre as obras, $62,5 \%$ não abordaram o critério "aplicação biotecnológica", ou o fizeram de modo insuficiente. Dos 37,5\% restantes, somente LD4 atende de forma plena a exigência. Quanto ao critério "adaptações bioquímicas" foi notado que $87,5 \%$, obtiveram nota igual ou inferior ao considerado parcialmente satisfatório (nota 3), sendo que apenas LD2 obteve nota máxima.

A abordagem plena e especificada dos grupos dos micro-organismos extremófilos, tais como metanogênicos, halófilos, psicrófilos, termófilos, acidófilos, dentre outros foi adotado em $62,5 \%$ das obras didáticas analisadas (Figura 3).

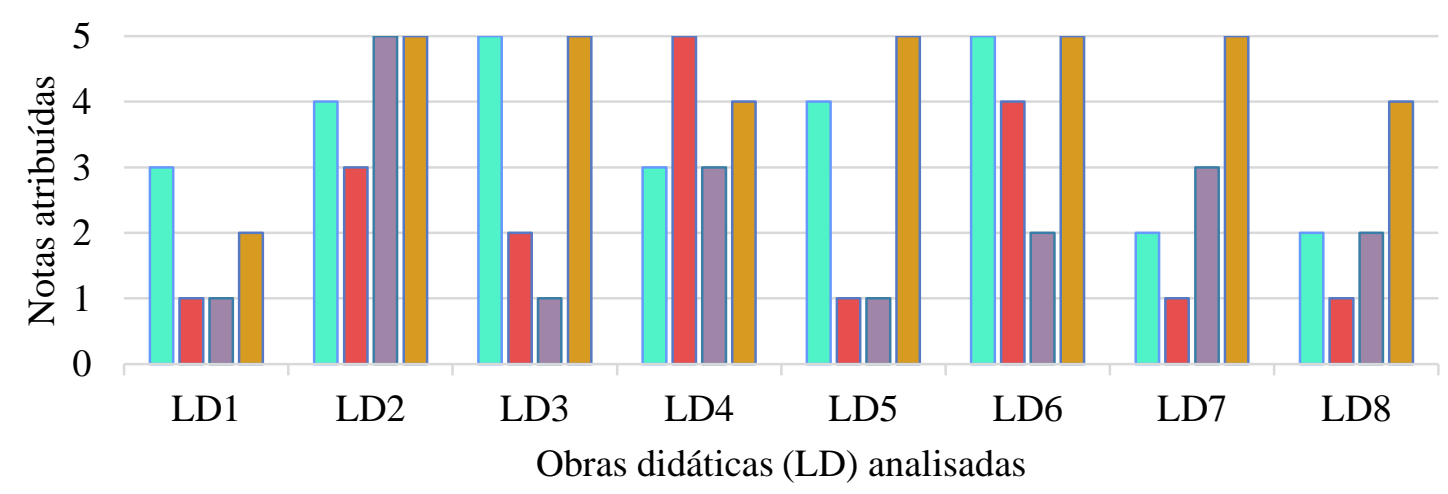

$\square$ Contextualização e integração com outros temas

Aplicações biotecnológicas

$\square$ Adaptações bioquímicas

$\square$ Abordagem dos diferentes grupos de procariontes extremófilos

Figura 3: Notas atribuídas às obras didáticas, por escala numérica adaptada de Peixe et al. (2017) [6], a o aspecto Interdisciplinaridade e Contextualização, segundo os diferentes critérios avaliados $e$ parametrizados pelo PNLD 2018. 


\section{DISCUSSÃO}

Os critérios de "Coerência entre fundamentação teórica e: imagens, textos e exercícios propostos", e "uso de vocabulário adequado e atualizado", apresentam-se plenamente satisfeitos em todas as obras didáticas. No entanto, a LD5 apresenta o título referente ao capítulo 2 como "Vírus e Bactérias", ao passo que no decorrer do capítulo, discorre sobre vírus, bactérias e arqueas. Apesar das arqueas compartilharem algumas características com as bactérias como por exemplo: ausência de envelope nuclear, organelas não envolvidas por membranas e cromossomo circular; elas também têm características exclusivas, tais como lipídeos de membrana formados por hidrocarbonetos ramificados e capacidade de crescimento em temperaturas superiores a $100^{\circ} \mathrm{C}$ (algumas espécies). Tais características diferenciais e comprovadas por técnicas modernas de biologia molecular, fizeram com que os cientistas alocassem as arqueas em um grupo de classificação biológica (táxon) distinto, denominado Archaea [7]. Dessa forma, não sendo as arqueas pertencentes ao domínio Bacteria, o livro deveria referir-se a elas enquanto "bactérias extremófilas" e não somente como bactérias, assim como apresentado pela LD7.

Erros conceituais observados em livros didáticos de biologia, em outras áreas de estudo dessa ciência $[8,9,10]$, corroboram a necessidade de uma análise mais aprofundada por parte dos professores para se evitar contradições e concepções dúbias e/ou equivocadas, que podem comprometer o conhecimento apresentado aos discentes.

As notas recebidas sobre o critério "quantidade de páginas" dedicadas às arqueas, não incidem como determinantes para a contextualização com outros temas, sobre as obras didáticas analisadas no presente estudo. A exemplo, LD1, LD2, LD4 e LD5, que obtiveram notas entre 5 e 4 no critério de páginas, apresentaram notas respectivas 3, 4, 3 e 4, relacionadas à integração com outros temas, demonstrando um retrato não tão satisfatório, uma vez que somente as obras didáticas LD3 e LD6 mantiveram as notas correspondentes em ambos os critérios. Por sua vez, LD7 e LD8 obtiveram notas de quantidade de páginas 4 e 3 , respectivamente, e de contextualização, 2 . Tais resultados são diferentes dos observados por Batista, Cunha e Cândido (2010) [11], que apesar de não relacionarem a quantidade de páginas à contextualização da temática "vírus", verificaram que alguns autores deram maior importância ao estudo dos vírus do que outros, discorrendo sobre o assunto ao longo de mais páginas.

Em todos os livros a temática "bactérias extremófilas / arqueas" foi abordada no conteúdo Domínios Biológicos devido à importância de dar-se ênfase à diferença entre os cinco Reinos e os três Domínios taxonômicos de classificação dos seres vivos propostos por Carl Woese. Somente em quatro obras a temática é abordada dentro dos conteúdos de Biotecnologia e Quimiossíntese. Do restante, três obras didáticas (LD4, LD7 e LD8) não trazem arqueas vinculado o conteúdo Quimiossíntese, sendo que LD8 no capítulo "Vida e Energia", que trata sobre os processos de metabolismo energético, nem mesmo o conteúdo de Quimiossíntese é apresentado, sendo tal aspecto considerado como déficit grave, haja visto que o processo quimiossintético é uma das principais formas de obtenção de energia do meio ambiente por alguns micro-organismos extremófilos [12].

No conteúdo de Biotecnologia, LD2, LD3, LD4, LD6 fazem referência a aplicação das arqueas. $\mathrm{O}$ uso das arqueas para a produção de gás combustível a partir do metano e na Reação em Cadeia de Polimerase - PCR (técnica utilizada para amplificar o ácido desoxirribonucleico - DNA), são as aplicações mais abordadas. Além destas, são exemplificados usos das arqueas na indústria de limpeza e indústria tecnológica. Outros temas que também poderiam ser abordados relacionam-se às indústrias alimentícia, têxtil e de mineração, áreas nas quais as arqueas vem se destacando com o avanço da ciência. Para Barbosa e Oliveira (2015) [13] a ausência da correlação entre a microbiologia e os aspectos práticos e cotidianos, dificulta uma aprendizagem mais concreta e significativa desses organismos, podendo trazer prejuízos à formação integral dos discentes, especialmente quando isso está associado a outros obstáculos enfrentados pelos professores em sala de aula, como por exemplo a deficiência física estrutural de muitas instituições de ensino básico do país que não têm laboratório de ciências [14].

O grupo de arqueas amplamente usado como exemplo na maioria dos livros são as bactérias metanogênicas, seguido, dos micro-organismos termófilos, que estão presentes em $87,5 \%$ das obras analisadas. Tais dados evidenciam o fato majoritário da concentração de estudos científicos em 
aplicações biotecnológicas empregando arqueas metanogênicas e termófilas, e suas consequentes divulgações.

Não há grande destaque ao conteúdo Adaptações Bioquímicas nos livros. Somente LD2, LD4, LD6, LD7 e LD8 abordam o assunto, de forma simplória. Destes, somente LD2 cumpriu plenamente o requisito. Em geral, o tema mais abordado neste tópico refere-se à constituição da parede celular das arqueas, na qual não há peptidoglicanos em sua constituição. Nesse ponto observa-se também uma deficiência dos livros em apresentar aos leitores as estruturas e mecanismos bioquímico-fisiológicos gerais que permitem com que tais micro-organismos se diferencie dos procariontes do domínio Bacteria e consigam suportar fatores ambientais inóspitos. Sabe-se, por exemplo, que a maior resistência das arqueas às altas temperaturas deve-se além de outros fatores, da constituição de uma membrana plasmática formada por uma monocamada de fosfolipídios com ligação do tipo éter, mais estável que a bicamada lipídica com ligação do tipo éster encontrado nas células dos outros seres vivos $[12,15]$.

Os iconográficos apresentados em maior quantidade, presentes em $75 \%$ das obras, referem-se à divisão de Reinos e Domínios. Estes são apresentados em forma de quadros, tabelas e árvores filogenéticas, inseridos em uma breve discussão sobre a divisão entre os três domínios, sendo que LD6, não explica o embasamento para esta classificação, nem ao menos atribui os créditos a um dos principais contribuintes da divisão taxonômica, Carl Woese. O segundo iconográfico mais utilizado é o de fontes termais oceânicas, presente em $62,5 \%$, o que em partes está associado aos principais grupos empregados na maioria das obras didáticas como exemplos de arqueas: metanogênicas e termófilos; seguido de $25 \%$ de iconográficos que associam arqueas a águas extremamente salinas. Pelo alto percentual de alguns tipos de iconográficos (quadros, tabelas e árvores filogenéticas) foi notado uma padronização na escolha de imagens pelos autores priorizando umas em detrimento de outras. Tal observação vai de encontro com pesquisa qualitativa de imagens nos livros de biologia referendados pelo PNLD 2012, para os conteúdos de genética e evolução, realizada por Badzinski e Hermel (2015) [16], e demonstra o mal aproveitamento desse recurso para facilitar a aprendizagem, especialmente quando de seu uso mais variado possível.

\section{CONCLUSÃO}

A deficiência observada em certos critérios analisados nesse estudo, para algumas das obras didáticas avaliadas são passíveis de promover maior superficialidade ou mesmo deficiência na aprendizagem discente, podendo inclusive repercutir na transmissão de conhecimentos fragmentados e concepções errôneas sobre o assunto.

Faz-se importante frisar, que os resultados encontrados não visam enaltecer ou desmerecer as obras didáticas analisadas, mas sim fazer apontamentos sobre a importância de uma análise mais minuciosa pelo docente, antes da adoção do material, ou quando já adotado, conscientizá-lo de alertar e fazer considerações aos alunos.

\section{REFERÊNCIAS BIBLIOGRÁFICAS}

1. Freire P. A importância do ato de ler - em três artigos que se completam. 46 ed. São Paulo: Cortez Editora; 2017. 104 p.

2. Furlan CC, Maio ER. Educação na modernidade líquida: entre tensões e desafios. Rev Mediações. 2016;21(2):279-302, doi: 10.5433/2176-6665.2016v21n2p279.

3. Nicola JA, Paniz CM. A importância da utilização de diferentes recursos didáticos no ensino de ciências e biologia. InFor, Inov. Form., Rev. NEaD-Unesp. 2016 Maio;2(1):355-81.

4. Brasil. PNLD 2018: biologia - guia de livros didáticos - Ensino Médio. Brasília: Ministério da Educação, Secretaria de Educação Básica; 2017. 39 p.

5. Coker JA. Extremophiles and biotechnology: current uses and prospects. F1000Res. 2016;5, doi: 10.12688/f1000research.7432.1.

6. Peixe PD, Pinheiro LG, Araújo MFF, Moreira SA. Os temas de DNA e Biotecnologia em livros didáticos de biologia: abordagem em ciência, tecnologia e sociedade no processo educativo. Acta Sci. 2017 Jan./Fev.;19(1):177-91.

7. Reece JB, Wasserman SA, Urry LA, Cain ML, Minorsky PV, Jackson RB. Biologia de Campbell. 10. ed. Porto Alegre: Artmed; 2015. 1488 p. 
8. Costa LC, Pansera-de-Araújo MC, Bianchi V. Sistemas digestório, respiratório e circulatório humanos em livros didáticos de Biologia de Ensino Médio. Bio-graf. 2017 Ene/Jun;10(18):19-27. doi: $10.17227 / 20271034$

9. Silva LCD, Nocelli RCF, Bozzini ICT. Abordagem de células em materiais didáticos. Rev Ciênc Tecnol Amb. 2015;1(1):28-34.

10. Silva AC, Menolli Junior N. Análise do conteúdo de fungos nos livros didáticos de Biologia do Ensino Médio. Rev Ciên Ideias. 2016 Set./Dez.; 7(3):235-73, doi: 10.22407/issn.2176-1477.2016v7i3619.

11. Batista MVA, Cunha MMS, Cândido AL. Análise do tema virologia em livros didáticos de biologia do ensino médio. Ens Pesq Educ Ciênc. 2010 Jan./Abr.;12(1):145-58. doi: 10.1590/1983-21172010120109.

12. Madigan MT, Martinko JM, Bender KS, Buckley DH, Stahl DA. Microbiologia de Brock. 14. ed. Porto Alegre: Artmed; 2016. 1032 p.

13. Barbosa FG, Oliveira NC. Estratégias para o ensino de microbiologia: uma experiência com alunos do ensino fundamental em uma escola de Anápolis-GO. Rev Ens Educ Ciênc Hum. 2015 Jan.;16(1):5-13. doi: 10.17921/2447-8733.2015v16n1p5-13.

14. Caetano GL, Pereira GR. O ensino sobre as bactérias e as arqueas na educação básica: proposição de um curso de formação docente. Lat Am J Sci Educ. 2019;6(12019):1-9.

15. Nelson DL, Cox MM. Princípios de Bioquímica de Lehninger. 7. ed. Porto Alegre: Artmed; 2019. 1272 p.

16. Badzinski C, Hermel EES. A representação da genética e da evolução através de imagens utilizadas em livros didáticos de biologia. Ens Pesq Educ Ciênc. 2015 Maio/Ago;17(2):434-54. 